\title{
Electrochemical Determination of 2,4-Dichlorophenoxyacetic Acid using Bismuth Film Modified Screen-printed Carbon Electrode
}

\author{
Temesgen Takele Niguso, Tesfaye Refera Soreta* ${ }^{\S}{ }^{\S}$, and Ephrem Tilahun Woldemariam \\ Jimma University, College of Natural Sciences, Department of Chemistry, P.O. Box 378, Jimma, Ethiopia.
}

Received 31 August 2017, revised 3 October 2018, accepted 2 November 2018.

\begin{abstract}
In this work, the development of an electrochemical method for the determination of 2,4-dichlorophenoxy acetic acid (2,4-D) (indirectly by converting to its electroactive nitrated form) using a modified screen-printed carbon electrode with bismuth film is reported. The electrode modification has been done by a single potential step electrodeposition of bismuth film on screen-printed carbon electrodes. Under the optimized conditions, the nitrated 2,4-D showed a dynamic linear concentration range in $\mathrm{pH} 11$ buffer from 11.1 to $74.3 \mu \mathrm{M}$ with regression coefficient $(\mathrm{R})$ of 0.9988 . The limits of detection and quantification were $3.15 \mu \mathrm{M}$ and $10.5 \mu \mathrm{M}$, respectively. The proposed method offered higher sensitivity compared to bare screen-printed carbon electrodes. The modified electrode showed good reproducibility, repeatability, stability and recovery for the analysis of 2,4-D. The developed method was used for electroanalysis of 2,4-D in soil and water samples collected from Sito Kebele, Dedo district Jimma zone.
\end{abstract}

KEYWORDS

Electroanalysis, herbicide, screen-printed carbon electrodes, bismuth film, 2,4-dichlorophenoxyacetic acid.

\section{Introduction}

Electroanalysis can be used as one of the potential analytical methods for the analysis of heavy metal ions in different environments, ${ }^{1}$ organic pollutants consisting of hydrazine, phenol, ${ }^{2}$ in biomedical packages for the detection of glucose, ${ }^{3}$ hormones, ${ }^{4}$ cells, ${ }^{5}$ and tumors markers. ${ }^{6}$ It is used in the detection of extraordinarily low levels of macromolecules like proteins ${ }^{7}$ and nucleic acids. ${ }^{8}$ In pharmaceuticals industries, it is used for the determination of the level of the components of drugs. ${ }^{9,10}$ Furthermore, it is a tool for the detection and determination of electroactive organic compounds used for pest and herb control. ${ }^{11}$

Even though numerous techniques had been reported for the determination of 2,4-D (consisting of high performance liquid chromatography. ${ }^{12}$ and gas chromatography coupled with mass spectrometry and spectrophotometry ${ }^{13}$ ), there are few electroanalytical techniques reported for the determination of herbicide 2,4-D using traditional carbon electrodes and mercury electrodes. ${ }^{14,15,16}$ The 2,4-D and its by-product reveal slow electron transfer, suggesting that the redox method is electrochemically irreversible. The electroinactivity of $2,4-\mathrm{D}$ has been reported and the determination of this compound through electrochemical strategies is not straightforward at present. ${ }^{17}$ So, to determine 2,4-D and its residue with the aid of electrochemical methods, the conversion of electroinactive 2,4-D to its electroactive species is required, and this has been accomplished by labelling it with a nitro group.

Electroanalytical methods have received a great deal of interest because of their simplicity, portability, lower detection limit, and inexpensiveness because of its good sensitivity, reduction in solvent and sample consumption, high-speed analysis, portability as well as simplicity. ${ }^{18}$ With the advancement in electroanalytical science, traditional carbon electrodes and mercury electrodes are cumbersome to use. ${ }^{19}$ Traditional carbon elec-

* To whom correspondence should be addressed. E-mail: tesfaye.refera @ ju.edu.et trodes require polishing and electrode treatments whereas mercury electrodes are inconvenient due to their well-known toxicity. Furthermore, in electroanalytical techniques, working electrodes might be insensitive to use in the detection of a few chemical substances. So electrode surface modification is needed to enhance the sensitivity, selectivity and stability of the electrodes to acquire enhanced response for analytical need..$^{20}$ For this reason, disposable screen-printed carbon electrodes (SPCEs) have proven to replace the above-mentioned electrodes with the surface modification by immobilization of a modifying agent on the electrode surface. Because SPCE avoids contamination and also eliminates problems which include the lack of responses due to surface fouling of the electrodes as it is used once and then discarded. ${ }^{21}$

Therefore, in this work, we report the development of an electroanalytical technique using a disposable screen-printed carbon electrode modified with a bismuth film for electroanalysis of 2,4-D.

\section{Materials and Methods}

\subsection{Chemicals}

Bismuth nitrate $\left(\mathrm{Bi}\left(\mathrm{NO}_{3}\right)_{3} \cdot 5 \mathrm{H}_{2} \mathrm{O}, 98 \%, \mathrm{M}\right.$ \& B laboratory reagent); boric acid $\left(\mathrm{H}_{3} \mathrm{BO}_{3}, 99.5 \%\right.$, Techno Pharmachem), 2,4-Dichlorophenoxyacetic acid $\left(\mathrm{C}_{8} \mathrm{H}_{6} \mathrm{O}_{3} \mathrm{Cl}_{2}, 97 \%\right.$, Aldrich), sodium perchlorate $\left(\mathrm{NaClO}_{4}, 98 \%\right.$, Sigma), potassium nitrate $\left(\mathrm{KNO}_{3}, 99-100.5 \%\right.$, Riedel de Haen), dichloromethane $\left(\mathrm{CH}_{2} \mathrm{Cl}_{2}\right.$, $\mathrm{BDH})$, hydrochloric acid $(\mathrm{HCl}, 37 \%$, Riedel de Haen), potassium hexacyanoferrate $\left(\mathrm{K}_{3} \mathrm{Fe}(\mathrm{CN})_{6}, 97 \%\right.$, Labmark Chemicals), sodium hydroxide $(\mathrm{NaOH}, 96 \%$, LeSOL laboratory reagent), potassium chloride $(\mathrm{KCl}, 99 \%$, Finkem), phosphoric acid $\left(\mathrm{H}_{3} \mathrm{PO}_{4}, 85 \%\right.$, Riedel de Haen), glacial acetic acid $\left(\mathrm{CH}_{3} \mathrm{COOH}\right.$, $100 \%, \mathrm{BDH})$, Britton Robinson (BR) buffer were used as received without any treatment. For aqueous solution preparations double-distilled water was used. 


\subsection{Instruments}

Screen-printed carbon electrodes (Dropsens 110) connected to Epsilon (BASI) electroanalyzer using Dropsens connector (DRP-DSC70506) were used for electrochemical measurements. The BASi Epsilon was operated using Basic Epsilon EC-Version 1.40.70 software. An ATC pH meter (353) was used to measure $\mathrm{pH}$.

\subsection{Methods}

\subsubsection{Procedure for Nitration of 2,4-D}

Nitrated 2,4-D was synthesized using the procedure reported by Maleki et al. ${ }^{17}$ Briefly, $2 \mathrm{~g}$ of 2,4-D was dissolved in $2 \mathrm{~mL}$ dichloromethane, and this solution was transferred to $5 \mathrm{~mL}$ concentrated sulfuric acid kept in ice bath at $0-5{ }^{\circ} \mathrm{C}$. While the temperature of the solution was maintained at $0-5{ }^{\circ} \mathrm{C}, 1.5 \mathrm{~mL}$ concentrated nitric acid was added dropwise over $30 \mathrm{~min}$ to the above solution. A yellow paste was formed in the vessel. The reaction mixture was then transferred into $30 \mathrm{~mL} 10 \%$ aqueous $\mathrm{Na}_{2} \mathrm{SO}_{4}$ and the separated organic phase was washed with $20 \mathrm{~mL}$ $10 \%$ aqueous $\mathrm{Na}_{2} \mathrm{SO}_{4}$, dried over anhydrous $\mathrm{Na}_{2} \mathrm{SO}_{4}$ in a desiccator, and the solvent was evaporated. The dried yellow solid was weighed, the yield of nitrated 2,4-D was calculated and it was found to be more than $97 \%$. The melting point of the solid compound was measured and it ranged from 141 to $143^{\circ} \mathrm{C}$.

\subsubsection{Procedure for Preparation of Solution}

Stock solution of nitrated 2,4-D $(3.72 \mathrm{mM})$ was prepared in $25 \mathrm{~mL}$ volumetric flask, by dissolving $25 \mathrm{mg}$ of the nitrated 2,4-D in a Britton Robinson (BR) buffer of $\mathrm{pH} 11$. The $\mathrm{pH}$ of BR buffer was adjusted to the desired level using $1 \mathrm{M} \mathrm{NaOH}$ solution. The working solution was prepared by taking an appropriate volume from the stock solution and diluting it with a buffer of pH 11 .

\subsubsection{Electrochemical Measurements}

The cyclic voltammetry and amperometric experiments were carried out using a BASi Epsilon voltammetric analyzer (Bio-analytical Systems, USA), controlled with basic Epsilon software EC-Version 1.40.70. The screen-printed carbon electrode (SPCE) (Dropsens 110) was used with carbon as the working electrode and carbon counter electrode and silver as pseudo reference electrode. The potentials reported in all electrochemical measurements were against this reference electrode. A magnetic stirrer (BASi C3 Cell stand) was used for stirring the solutions during amperometric measurements.

\subsubsection{Electrode Cleaning and Conditioning}

SPCEs were first thoroughly flushed with distilled water. The electrochemical conditioning of the electrode was followed by potential scanning from 0 to $1100 \mathrm{mV}$ in $1 \mathrm{M} \mathrm{KCl}$ for at least five complete scans at $100 \mathrm{mV} \mathrm{s}^{-1}$, during which the high background current due to carbon oxidation was minimized. Then, the $\mathrm{CV}$ of bare screen-printed electrodes in the presence of potassium hexacyanoferrate was measured from $-200 \mathrm{mV}$ to $400 \mathrm{mV}$ to determine the area of the electrodes. The electrodes were dried and immediately used following the cleaning and conditioning steps.

\subsubsection{Preparation of Bismuth Film Modified SPCE (BiFE)}

Bismuth film modified screen-printed carbon electrodes (BiFE) were prepared by potentiostatic deposition of bismuth on screen-printed carbon electrodes (SPCE) in a Bi(III) bath. Briefly, a constant deposition potential of $-1050 \mathrm{mV}$ for $180 \mathrm{~s}$ was applied to the SPCEs in a bismuth deposition bath $\left(2 \mathrm{mM} \mathrm{Bi}\left(\mathrm{NO}_{3}\right)_{3} .5 \mathrm{H}_{2} \mathrm{O}\right.$ in $1 \mathrm{M} \mathrm{HCl})$. The modified SPCEs were rinsed with distilled water and immediately used for electrochemical studies of nitrated 2,4-D.

\subsubsection{Modifying Strategies of the Electrodes using Bismuth Films}

Parameters for the plating of the screen-printed carbon electrode with bismuth were studied using cyclic voltammetry and chronoamperometry methods based on electrochemical response for the analyte at the electrodes. Plating solution containing Bi (III) in acidic media was used to avoid hydrolysis of the metal cation..$^{22}$ Parameters such as initial concentration of the deposition bath, the deposition potential and deposition time were optimized for the electrodeposition of bismuth films. The optimum conditions were selected based on response to the analyte electrochemical signal.

\section{i. Optimization of deposition time}

As reported by Tufa et al., ${ }^{23}$ a bismuth film was deposited on the SPCE from a $2 \mathrm{mM}$ Bi (III) deposition bath at a step potential of $-1200 \mathrm{mV}$. The effect of deposition time was studied by varying the duration of the applied potential for 60, 120, 180, 240,300 and $360 \mathrm{~s}$. Using the as prepared Bi-film electrodes, the current response for $0.372 \mathrm{mM}$ nitrated 2,4-D was recorded $(\mathrm{n}=3)$. The appropriate deposition time was selected based the response for the nitrated 2,4-D.

\section{ii. Optimization of deposition potential}

The Bi film deposition potential was optimized within the potential range from $-950 \mathrm{mV}$ to $-1250 \mathrm{mV}$ as dictated by the $\mathrm{CV}$ of $2 \mathrm{mM} \mathrm{Bi}\left(\mathrm{NO}_{3}\right)_{3}$ at the SPCE. After deposition of the Bi film at selected potentials within this range for $180 \mathrm{~s}$, the modified SPCE was used to measure the reduction peak for $0.372 \mathrm{mM}$ of the nitrated 2,4-D ( $\mathrm{n}=3)$. The deposition potential that gave the highest analytical signal was selected.

iii. Optimization of bath concentration

Bismuth deposition bath concentrations that range from $0.5 \mathrm{mM}$ to $3 \mathrm{mM}$ was tested to optimized bath concentration at $-1050 \mathrm{mV}$ deposition potential for $180 \mathrm{~s}$. For each concentration tested, triplicate measurement was made for the reduction of the nitrated 2,4-D at the Bi film modified electrodes and the average current obtained from different deposition baths was compared to selected the appropriate deposition bath concentration.

\section{iv. Optimization of $\mathrm{pH}$}

For $\mathrm{pH}$ optimization, the amperometry of $0.372 \mathrm{mM}$ nitrated 2,4-D was run at Bi film modified SPCE (obtained from deposition bath of $2 \mathrm{mM}$, at $-1050 \mathrm{mV}$ for $180 \mathrm{~s}$ ), using the optimized deposition potential, deposition time and concentration. The resulting current signal (average of triplicate measurement) of the nitrated 2,4-D were plotted against the $\mathrm{pH}$ of the buffer solution. The $\mathrm{pH}$ which gave the highest analytical signal was selected.

\section{v. Procedure for collecting data for the calibration curve}

Three SPCEs were modified with bismuth film using the selected optimized condition. The amperometry at an applied potential $-550 \mathrm{mV}$ of nitrated 2,4-D for concentrations ranging from 11.1 to $74.3 \mu \mathrm{M}$ was run on the same day under similar conditions using these modified electrodes. The average current signal of the analyte from the modified electrodes was plotted against the concentration of nitrated 2,4-D and the calibration curve was plotted.

Three bare SPCE were taken and the chronoamperometry of nitrated 2,4-D at an applied potential of $-550 \mathrm{mV}$ for concentra- 
tions ranging from 22.3 to $59.5 \mu \mathrm{M}$ were run. The average current signal of the analyte from the three different electrodes was plotted against the concentration of nitrated 2,4-D.

vi. Procedure for testing reproducibility and repeatability

The reproducibility of the bismuth film modified SPCEs was examined by measuring the same concentration $(37.2 \mu \mathrm{M})$ of nitrated 2,4-D on three modified electrodes on three consecutive days with triplicate measurement on each day. The relative standard deviation (RSD) of the measured current signal was calculated to determine reproducibility of the modification strategy among the electrodes.

For the repeatability study, the bismuth film modified electrode was prepared under the optimum conditions. Nine successive voltammetric measurements of $37.2 \mu \mathrm{M}$ nitrated 2,4-D were made on the same day for a modified electrode. The RSD of the measurements was used to estimate the repeatability of the measurement.

vii. Procedure for stability study

Three SPCE were modified with bismuth film under the optimized conditions on the same day. The amperometry of 37.2 $\mu \mathrm{M}$ nitrated 2,4-D was measured on the first day, seventh day and fourteenth day. On each day, six measurements were made at an electrode. The average current signals of the six measurements in the first day were compared to those of the fourteenth day to determine the stability of the modification procedure developed.

\subsubsection{Procedure for Sample Collection}

Soil and water samples were collected from Dedo district, Sito Kebele around Jimma zone, Ethiopia (UTM 799083N-846083N and 244535E-302787E). Six soil samples from one farmland were randomly collected following standard sampling procedure. The soil samples were mixed and finally one composite soil sample was obtained. In addition, a water sample was collected from Dase River in Sito Kebele about $200 \mathrm{~m}$ from the farmland.

\subsubsection{Procedure for the Extraction of 2,4-D from Water and Soil Samples}

i. Extraction of 2,4-D from soil samples

$1 \mathrm{~g}$ of air dried soil sample was dissolved in $100 \mathrm{~mL}$ of water and the $\mathrm{pH}$ of the solution was adjusted to $\sim 9$ with $1 \mathrm{M} \mathrm{NaOH}$ solution. Organic materials that could be present in the sample was separated using the procedure reported by Maleki et al. ${ }^{17}$ Briefly, $10 \mathrm{~mL}$ of the soil solution was transferred to a separating funnel. Then the $\mathrm{pH}$ of the aqueous solution was adjusted approximately to 1 with $1 \mathrm{M} \mathrm{HCl}$. Using $5 \mathrm{~mL}$ dichloromethane separation of the analyte was made. The dichloromethane phase (expected to contain 2,4-D) was back-extracted with $10 \mathrm{~mL}$ alkaline aqueous solution $(\mathrm{pH} \sim 9)$. The aqueous solution obtained was nitrated applying procedures reported by Maleki et $a l .{ }^{17}$ and then analyzed by the proposed electrochemical method.

\section{ii. Extraction of 2,4-D from water samples}

For the analysis of 2,4-D from water samples, $10 \mathrm{~mL}$ of water sample was transferred to a separating funnel. The $\mathrm{pH}$ of solution was adjusted to approximately 1 with $\mathrm{HCl}(1 \mathrm{M})$ and the separation was performed with $5 \mathrm{~mL}$ of dichloromethane. The organic phase was back-extracted with $10 \mathrm{~mL}$ alkaline solution ( $\mathrm{pH} \sim 9$ adjusted with $1 \mathrm{M} \mathrm{NaOH}$ ). The aqueous solution obtained was nitrated applying procedures reported by Maleki et al. ${ }^{17}$ Finally it was analyzed by the proposed electrochemical method.

\section{Results and Discussion}

\subsection{Cyclic Voltammetry of Bismuth (III) Ion}

The cyclic voltammogram of Bare SPCE in supporting electrolyte $(1 \mathrm{MHCl})$ and in $2 \mathrm{mM} \mathrm{Bi}\left(\mathrm{NO}_{3}\right)_{3} \cdot 5 \mathrm{H}_{2} \mathrm{O}$ in $1 \mathrm{MHCl}$ is shown in Fig. 1. From the cyclic voltammograms, the potential at which $\mathrm{Bi}^{3+}$ ion can be reduced to its metallic form was selected (potential lower than $-950 \mathrm{mV}$ ). The peak at $-1100 \mathrm{mV}$ corresponds to the reduction of $\mathrm{Bi}$ (III) ion whereas the peak around $-400 \mathrm{mV}$ corresponds to reduction of hydrogen ion from $\mathrm{HCl}$.

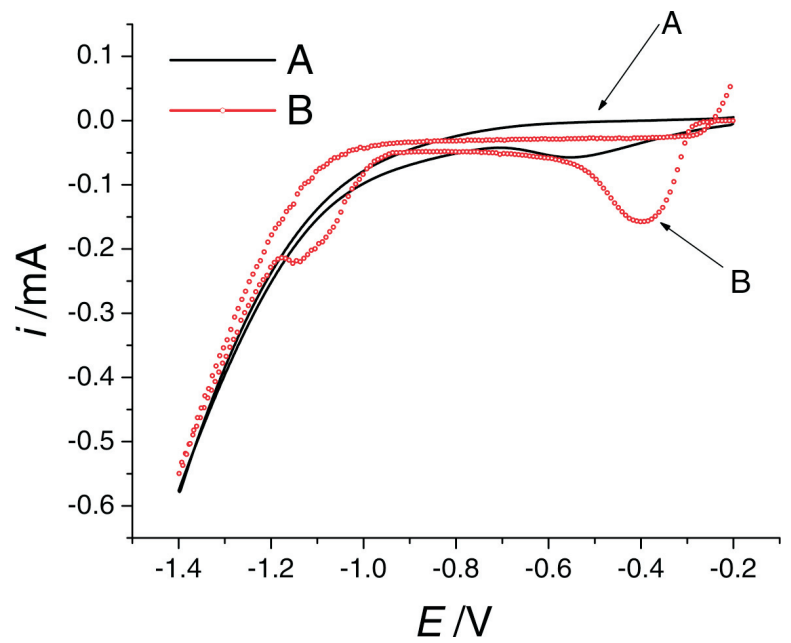

Figure 1 Cyclic voltammogram of (A) $1 \mathrm{MHCl}$ and (B) $2 \mathrm{mMBi}$ (III) ion in $1 \mathrm{M} \mathrm{HCl}$. In both cases bare SPCE was used at a scan rate of $100 \mathrm{mV} \mathrm{s}^{-1}$

\subsection{Electrochemical Characterization of Nitrated 2,4-D}

The cyclic voltammograms of nitrated 2,4-D at the bare, and bismuth film-modified SPCEs (BiFE) are shown in Fig. 2. The major reduction peaks observed for all the electrodes (curves A, $B, C$ and D) are associated with the reduction of hydrogen ions. For bismuth modified electrode cases, the reduction potential of hydrogen has shifted to more negative potentials since they have high overpotential for the reduction of $\mathrm{H}_{3} \mathrm{O}^{+}$to $\mathrm{H}_{2}$ similar to mercury electrodes. ${ }^{24}$ The minor peaks observed at around -300 to $-500 \mathrm{mV}$ (curves $\mathrm{A}$ and $\mathrm{C}$ ) are associated with the reduction of the nitrated 2,4- $\mathrm{D}^{16}$ at bare and Bi film modified SPE, respectively. It is evident that the voltammogram of BIFEs showed an increment in signal for the analyte than that of the bare SPCE within the studied potential window.

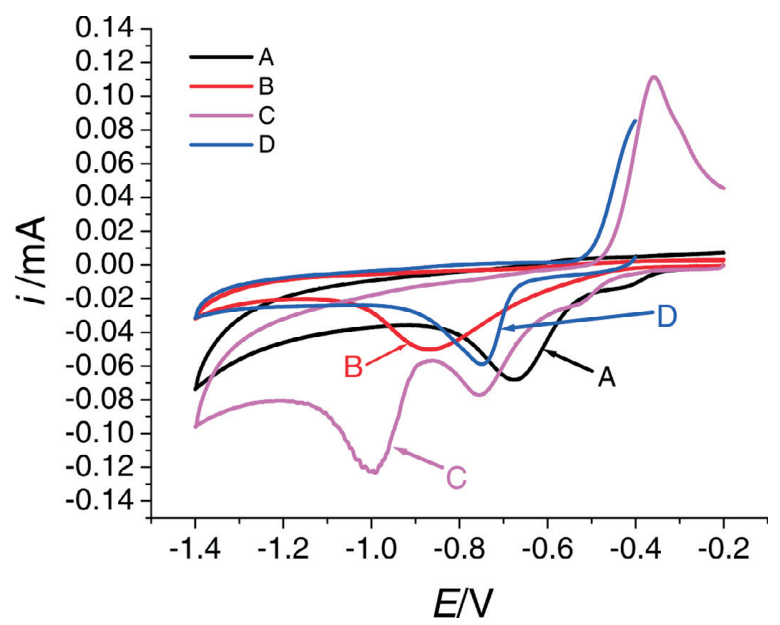

Figure 2 Cyclic voltammogram of (A) nitrated 2,4-D on bare SPCE (B) bare SPCE in buffer of $\mathrm{pH} 11,(\mathrm{C})$ nitrated 2,4-D on the bismuth modified SPCE, (D) bismuth modified SPCE in buffer of $\mathrm{pH} 11$. 


\subsection{Optimization of Parameters for the Determination 2,4-D}

\subsubsection{Effect of Deposition Potential}

The optimum potential for bismuth film deposition on the SPCE from the plating solution containing $2 \mathrm{mM}$ Bi (III) in $1 \mathrm{M}$ $\mathrm{HCl}$ was studied within the potential range of -950 to $-1250 \mathrm{mV}$. The best deposition potential was selected by comparing the modified electrode response towards $0.372 \mathrm{mM}$ nitrated 2,4-D (Fig. 3). The deposition potential of $-1050 \mathrm{mV}$ has given the best analytical signal and the BiFE obtained under these conditions was selected for the electroanalysis of nitrated 2,4-D. This result is in line with the effect of the choice of deposition potential to have best quality of bismuth film which was investigated by Kokkinos et al..$^{25}$ The selected deposition potential has also an additional advantage as it can eliminate the background hydrogen evolution that occurs at a more negative potential.

\subsubsection{Effect of Deposition Time}

The bismuth film deposition time is one of the decisive parameters which may control the thickness of the bismuth film. ${ }^{26}$ The effect of the bismuth plating time was studied in the range $60-360 \mathrm{~s}$ as shown in Fig. 4. The peak current of the nitrated 2,4-D goes on increasing with increasing bismuth deposition time up to $180 \mathrm{~s}$ and remains constant beyond this deposition time which suggest that the deposited layer of bismuth may have covered the surface of the electrode and substantial increment in film thickness prevented as a result of depletion of $\mathrm{Bi}^{3+}$ at electrodeelectrolyte interface..$^{23,26}$

\subsubsection{Effect of Bath Concentration}

The other important parameter which influences the thickness of bismuth film is the bismuth ion concentration on the peak current of the nitrated 2,4-D. The effect of concentration of bismuth ion was examined in the range of 0.5 to $3 \mathrm{mM}$ as shown in Fig. 5 for $0.372 \mathrm{mM}$ nitrated 2,4-D solution in buffer at $\mathrm{pH} 11$.

The result in Fig. 5 shows that the peak current of the nitrated 2,4-D started increasing up to $2 \mathrm{mM}$ Bi (III) ion and started decreasing for concentration beyond $2 \mathrm{mM}$ Bi (III) ion. The increase in peak current for the increase in Bi (III) ion concentration up to $2 \mathrm{mM}$ is attributed to the increase in the bismuth film thickness. ${ }^{27}$ However, when the concentration of Bi (III) ion becomes higher, peaks decreased with increasing bismuth film

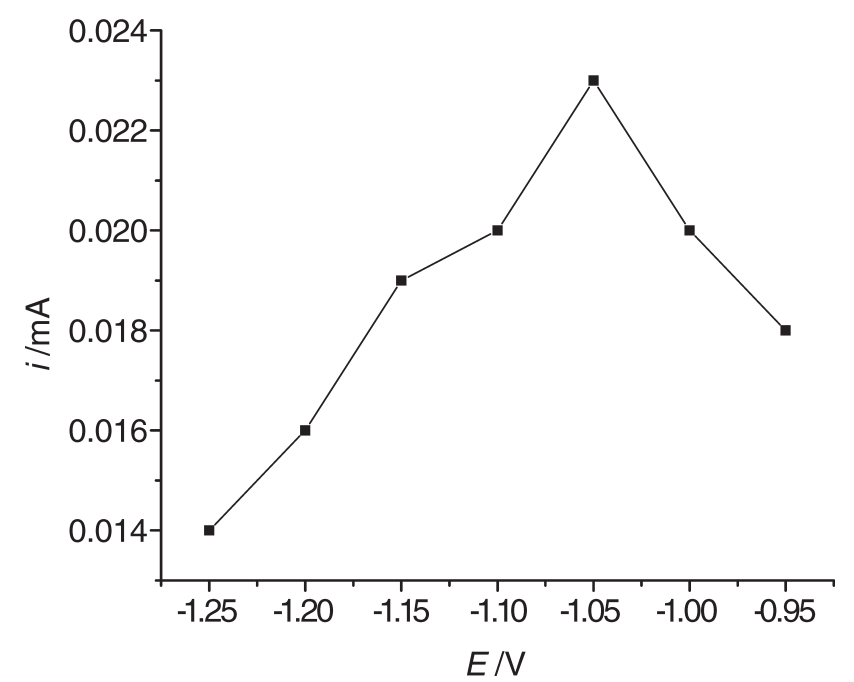

Figure 3 Effect of deposition potential upon voltammetric response for $0.372 \mathrm{mM}$ nitrated 2,4-D. Experimental conditions: $2 \mathrm{mM}$ Bi (III) and deposition time $180 \mathrm{~s}$, each data point represents an average of $\mathrm{n}=3$.

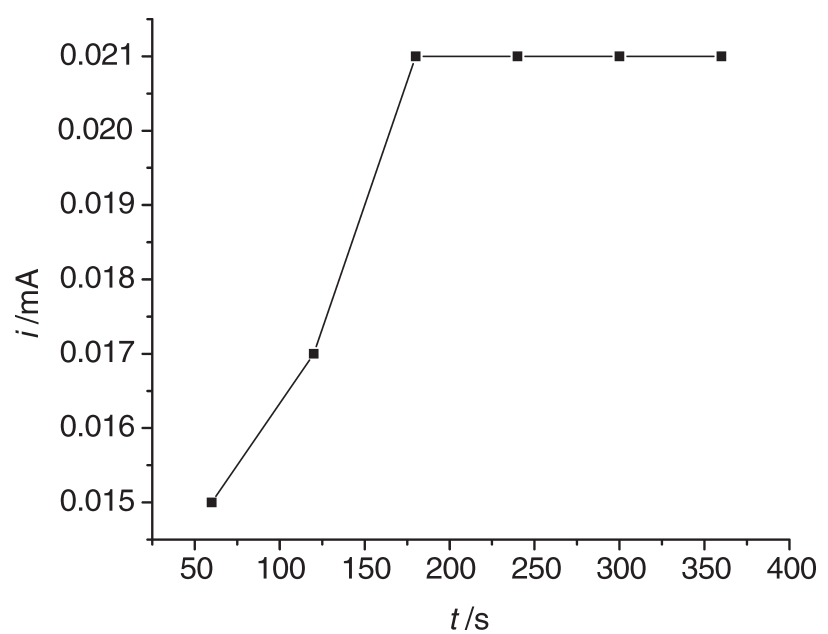

Figure 4 Effect of deposition time upon voltammetric response for $0.372 \mathrm{mM}$ nitrated 2,4-D. Experimental conditions: $2 \mathrm{mM}$ Bi (III) and deposition potential at $-1050 \mathrm{mV}$. Each data point represents an average of $\mathrm{n}=3$ measurements.

thickness due to cracking of the film at higher concentration. Hence, this result is in agreement with result reported for the optimization of bath concentration. ${ }^{23,26}$

\subsubsection{Effect of $p H$ of the Supporting Electrolyte}

$\mathrm{pH}$ of the electrolyte is an important parameter that could have significant influence on the response of the electrode in electroanalysis. It was studied in the $\mathrm{pH}$ range of $1-13$ in BR buffer. The results obtained is summarized in Fig. 6 in which the maximum response was observed at $\mathrm{pH} 11$.

This may be due to the anionic form of the analyte being the redox active component. In addition, it is not advisable to work in $\mathrm{pH}<6$ solutions as the reduction of the analyte interferes with the hydrogen evolution reaction. Therefore, a $\mathrm{pH} 11$ buffer was taken for the determination of 2,4-D throughout the experiments, in agreement with reports. ${ }^{17}$

\subsection{Repeatability and Reproducibility}

The repeatability and reproducibility BiFEs were determined by successive voltammetric measurements using $37.2 \mu \mathrm{M}$ nitrated 2,4-D in BR buffer solution at $\mathrm{pH} 11$. In the repeatability study, nine successive voltammetric measurements on the same

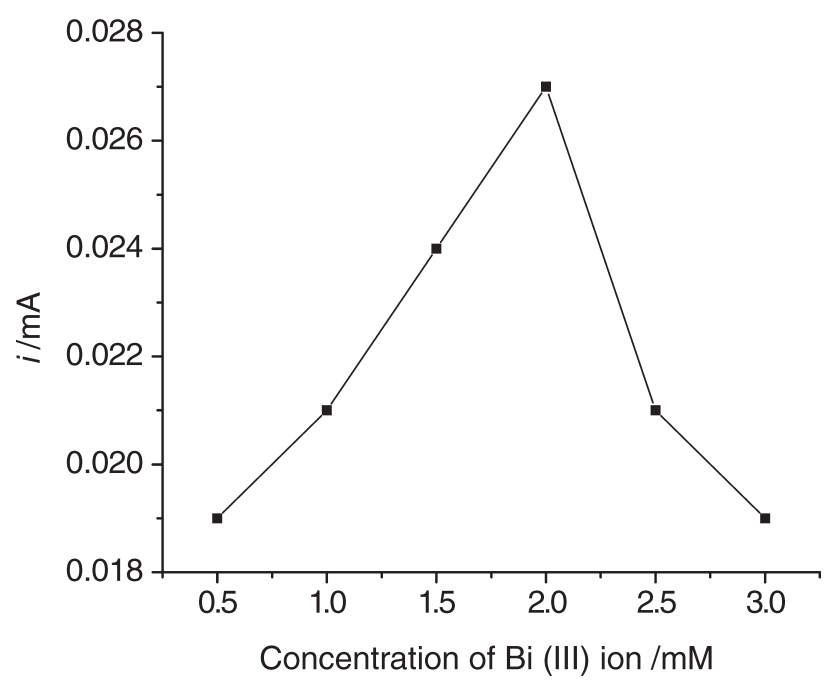

Figure 5 Effect of bath concentration upon voltammetric response for $0.372 \mathrm{mM}$ nitrated 2,4-D. Experimental condition: deposition potential $-1050 \mathrm{mV}$ and deposition time $180 \mathrm{~s}$. Each data point represents an average of $n=3$ measurements. 


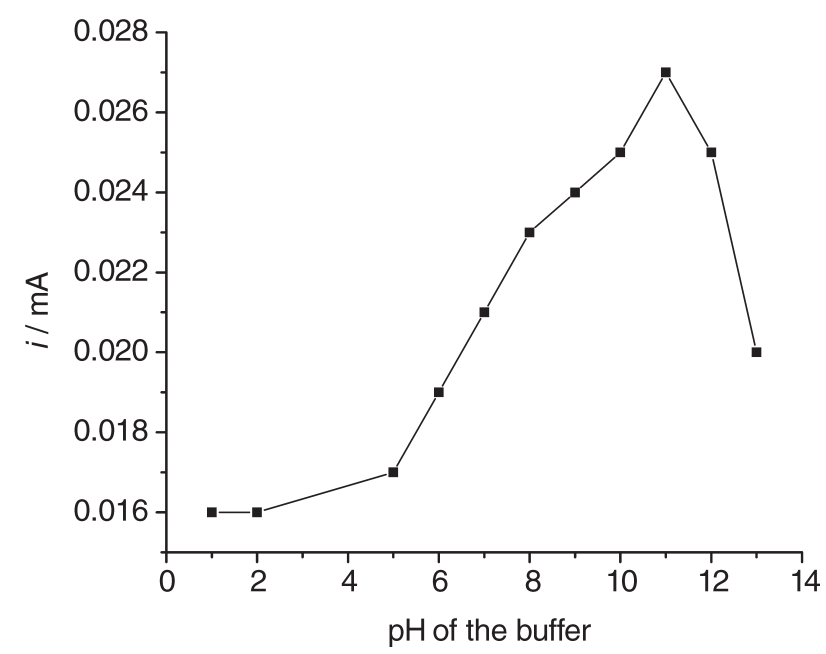

Figure 6 Effect of $\mathrm{pH}$ of the supporting electrolyte upon voltammetric response for a solution containing $0.372 \mathrm{mM}$ nitrated 2,4-D. Electrode Modification conditions: $2 \mathrm{mM} \mathrm{Bi} \mathrm{(III)} \mathrm{bath,} \mathrm{deposition} \mathrm{time} \mathrm{of} 180 \mathrm{~s}$ and deposition potential at $-1050 \mathrm{mV}$. Each data point represents an average of $\mathrm{n}=3$ measurements.

day were made under the same experimental condition, and the RSD was $5.84 \%$. This suggested that the proposed BiFEs have good repeatability.

The reproducibility of the BiFE was also examined by measuring 37.2 $\mu \mathrm{M}$ of nitrated 2,4-D on three different days with triplicate measurement. The RSD obtained were $4.66 \%$ for three independently prepared modified electrodes. This confirmed that the experimental results for the proposed BiFEs were reproducible.

\subsection{Stability of the BiFE}

The stability of the bismuth film modified SPCE after keeping it for two weeks was studied by amperometric measurements of $37.2 \mu \mathrm{M}$ nitrated 2,4-D. The mean peak current for 12 days measurement in two weeks for the nitrated 2,4-D was $0.01125 \mathrm{~mA}$ with RSD of 5.23. When we compare the initial current response (first day signal) to the mean, $93.75 \%$ of the original signal was maintained. This result indicated that there was small peak current change showing that the BiFE had good stability.

\subsection{Recoveries of 2,4-D from Soil and Water Samples}

For the recovery studies, $10 \mathrm{~mL}$ of each of the nitrated water and soil samples were transferred into the electrochemical cell. The recovery was performed by spiking three different concentrations of nitrated 2,4-D $(22.3,29.7$, and $37.2 \mu \mathrm{M})$ to each sample, and the resultant current peak of chronoamperometry was obtained using the proposed BiFEs.

The recovery obtained for $2,4-\mathrm{D}$ in the real samples using the bismuth film modified SPCE ranges from 93.8 to $107.1 \%$ as illustrated in (Table 1) for water and soil samples. These results may suggest that the matrices of the real samples do not have
Table 1 Recoveries of 2,4-D from real samples $(n=3)$.

\begin{tabular}{lcccc}
\hline Sample & Added $/ \mu \mathrm{M}$ & Recovered $/ \mu \mathrm{M}$ & Recovery $\%$ & RSD \% \\
\hline Water & 22.3 & 22.4 & 100.4 & 8.66 \\
& 29.7 & 31.8 & 107.1 & 5.97 \\
& 37.2 & 34.9 & 93.8 & 5.09 \\
Soil & 22.3 & 23.1 & 103.6 & 7.53 \\
& 29.7 & 31.8 & 107.1 & 5.41 \\
& 37.2 & 37.7 & 101.3 & 4.56 \\
\hline
\end{tabular}

significant effects on the determination of the 2,4-D from real water and soil samples.

\subsection{Determination of Detection Limit and Limit of Quantification}

The calibration curve was constructed under optimum experimental parameters for the determinations of low levels of nitrated 2,4-D with triplicate measurements (Fig. 7). The limit of detection (LOD) which is three times the standard deviation of the blank divided by the slope of the curve and limit of quantification (LOQ), which refers to ten times the standard deviation of the blank divided by the slope of the curve, were calculated to be 3.15 and $10.5 \mu \mathrm{M}$, respectively. As it is shown in the Fig. 7, the sensitivity of the bismuth modified SPCE is higher than that of the bare SPCE.

\subsection{Comparison of the Method Developed in this Work with the Literature}

The developed electroanalytical method for the determination of 2,4-D herbicide is compared with the values reported in the literature as shown in (Table 2). The proposed method has shown moderate performance.

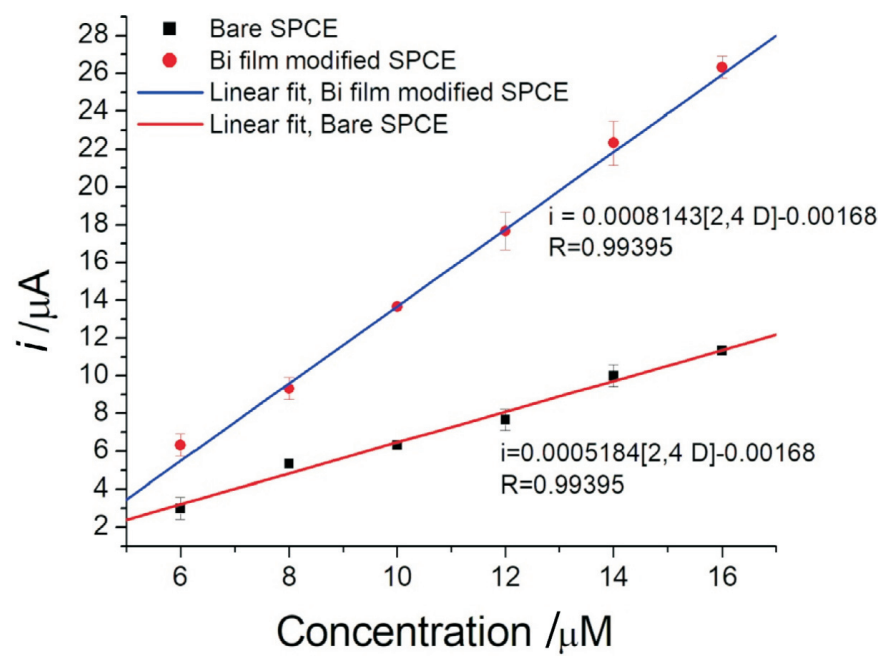

Figure 7 Comparison of the calibration curves for nitrated 2,4-D at the bismuth film modified SPCE and bare SPCE in a selected concentration range. For both modified and bare SPCE, the data points are an average

Table 2 Comparison of the developed method in the present work and other methods described in the literature for the determination of 2,4-D.

\begin{tabular}{llll}
\hline Electrodes & Techniques & LOD & Reference \\
\hline Protoporphyrin IX cobalt(III) chloride modified GCE & CA & $0.98 \mu \mathrm{M}$ & 28 \\
Silica-gel modified carbon paste electrode & CA & $0.400 \mu \mathrm{M}$ & 29 \\
Mercury electrode & ADS & $0.226 \mu \mathrm{M}$ & 30 \\
Static mercury electrode & DPV & $0.0226 \mu \mathrm{M}$ & 17 \\
Bismuth film modified SPCE & CA & $3.15 \mu \mathrm{M}$ & This work \\
\hline
\end{tabular}




\section{Conclusion and Recommendation}

In this study, an analytical method for the electroanalysis of 2,4-D using bismuth film modified SPCEs was developed. The method has shown a dynamic linear concentration range from 11.1 to $74.3 \mu \mathrm{M}$ of the nitrated 2,4-D with regression coefficient of (R)0.9988. The limits of detection and quantification were 3.15 and $10.5 \mu \mathrm{M}$, respectively. The method has exhibited very good electroanalytical properties such as high sensitivity, lower limit of detection (LOD) and wide linear dynamic range for the determination of 2,4-D. The method has advantages due to its inexpensiveness, simplicity, fast time analysis and lesser toxicity.

\section{Acknowledgements}

T.T. Niguso would like to thank Ambo University for partially supporting him for this work. The authors would like to thank Jimma University, School of Postgraduate Studies and Department of Chemistry for their invaluable material and financial support.

\section{${ }^{s}$ ORCID iD}

Tesfaye Refera Soreta: iD orcid.org/0000-0002-7808-254X

\section{References}

1 G. Achary, M. Kumaraswamy, R. Viswanatha and Y.A. Nayaka, An organically modified exfoliated graphite electrode for the voltammetric determination of lead ions in contaminated water samples, Russ. J. Electrochem., 2015, 51, 679-685.

2 K.C. Honeychurch and J.P. Hart, Voltammetric behavior of p-nitrophenol and its trace determination in human urine by liquid chromatography with a dual reductive mode electrochemical detection system, Electroanalysis, 2007, 19, 2176-2184; S. Sakthinathan and S.-M. Chen, Graphene supported nanocomposite for electrochemical detection of pollutant materials: a short review, Int. J. Electrochem., 2015, 10, 6527-6536.

3 A.S. Kumar and J.-M. Zen, Electrochemical investigation of glucose sensor fabricated at copper-plated screen-printed carbon electrodes, Electroanalysis, 2002, 14, 671-678.

4 A. La Marca, G. Stabile, A.C. Artenisio and A. Volpe, Serum antiMullerian hormone throughout the human menstrual cycle, Hum. Reprod., 2006, 21, 3103-3107.

5 S. Geetha, C.R. Rao, M. Vijayan and D. Trivedi, Biosensing and drug delivery by polypyrrole, Anal. Chim. Acta, 2006, 568, 119-125.

6 X. Wang, J. Yu, A. Sreekumar, S. Varambally, R. Shen, D. Giacherio, R. Mehra, J.E. Montie, K.J. Pienta and M.G. Sanda, Autoantibody signatures in prostate cancer, N. Engl. J. Med., 2005, 353, 1224-1235.

7 S. Zhang, H. Ma, L. Yan, W. Cao, T. Yan, Q. Wei and B. Du, Copperdoped titanium dioxide nanoparticles as dual-functional labels for fabrication of electrochemical immunosensors, Biosens. Bioelectron., 2014, 59, 335-341.

8 M.K. Schlegel, A.E. Peritz, K. Kittigowittana, L. Zhang and E. Meggers, Duplex formation of the simplified nucleic acid GNA, ChemBioChem, 2007, 8, 927-932.

9 C. Li, G. Zhan, Q. Yang and J. Lu, Electrochemical investigation of acetaminophen with a carbon nano-tube composite film electrode, Bull. Korean Chem. Soc., 2006, 27, 1854-1860.

10 Y. Wang, Y. Rui, F. Li and M. Li, Electrodeposition of nickel hexacyanoferrate/layered double hydroxide hybrid film on the gold electrode and its application in the electroanalysis of ascorbic acid, Electrochim. Acta, 2014, 117, 398-404.

11 L.C.S. De Figueiredo-Filho, V.B. dos Santos, B.C. Janegitz, T.B. Guerreiro, O. Fatibello-Filho, R.C. Faria and L.H. Marcolino-Junior,
Differential pulse voltammetric determination of paraquat using a bismuth-film electrode, Electroanalysis, 2010, 22, 1260-1266.

12 A. Jankowska, M. Biesaga, P. Drzewicz, M. Trojanowicz and K. Pyrzyn'ska, Chromatographic separation of chlorophenoxy acid herbicides and their radiolytic degradation products in water samples, Water Res., 2004, 38, 3259-3264.

13 S. Kundu, A. Pal and A.K. Dikshit, UV induced degradation of herbicide 2, 4-D: kinetics, mechanism and effect of various conditions on the degradation, Sep. Purif. Technol., 2005, 44, 121-129.

14 I. G. Casella and M. Contursi, Electrocatalytic reduction of chlorophenoxy acids at palladium-modified glassy carbon electrodes, Electrochim. Acta, 2007, 52, 7028-7034.

15 S. Chaiyasith, T. Tangkuaram and P. Chaiyasith, Electrocatalytical of chlorophenoxycarboxylic acids at a protoporphyrin IX cobalt (III) chloride modified glassy carbon electrode, J. Electroanal. Chem., 2005, $581,104-110$

16 F. Ramos de Andrade, R. Alves de Toledo and C. Manoel Pedro Vaz, Electroanalytical methodology for the direct determination of 2, 4-dichlorophenoxyacetic acid in soil samples using a graphitepolyurethane electrode, Int. J. Electrochem., 2014.

17 N. Maleki, A. Safavi, F. Hasanpour and H.R. Shahbaazi, Determination of traces of 2,4 dichlorophenoxy acetic acid in environmental samples, Sci. Iranica, 2008, 15, 430-434.

18 J. Wang, Analytical Electrochemistry, John Wiley \& Sons, 2006.

19 B. Uslu and S.A. Ozkan, Solid electrodes in electroanalytical chemistry: present applications and prospects for high throughput screening of drug compounds, Comb. Chem. High Throughput Screening, 2007, 10, 495-513.

20 N.R. Stradiotto, H. Yamanaka and M.V.B. Zanoni, Electrochemical sensors: a powerful tool in analytical chemistry, J. Braz. Chem. Soc., $2003, \mathbf{1 4}, 159-173$.

21 A. Hayat and J.L. Marty, Disposable screen printed electrochemical sensors: tools for environmental monitoring, Sensors, 2014, 14, 10432-10453.

22 N.V. Lezi, V. Vyskočil, A. Economou and J. Barek, Electroanalysis of organic compounds at bismuth electrodes: a short review, Sens. Electroanal., 2012, 7, 71-78.

23 L.T. Tufa, K. Siraj and T.R. Soreta, Electrochemical determination of lead using bismuth modified glassy carbon electrode, Russian J. Electrochem., 2013, 49, 59-66.

24 H. Sopha, S.B. Hocevar, B. Pihlar and B. Ogorevc, Bismuth film electrode for stripping voltammetric measurement of sildenafil citrate, Electrochim. Acta, 2012, 60, 274-277.

25 C. Kokkinos, A. Economou, I. Raptis and C.E. Efstathiou, Lithographically fabricated disposable bismuth-film electrodes for the trace determination of $\mathrm{Pb}(\mathrm{II})$ and $\mathrm{Cd}(\mathrm{II})$ by anodic stripping voltammetry, Electrochim. Acta, 2008, 53, 5294-5299.

26 J.A. Barãn-Jaimez, J.L. Marulanda-Arãvalo and J.J. Barba-Ortega, Electrodes friendly with the environment for detect heavy metal, DYNA (Colombia), 2014, 81, 122-128.

27 F. Arduini, J.Q. Calvo, G. Palleschi, D. Moscone and A. Amine, Bismuth-modified electrodes for lead detection, TrAC - Trends Anal. Chem., 2010, 29, 1295-1304.

28 S. Chaiyasith, T. Tangkuaram and P. Chaiyasith, Electrocatalytical of chlorophenoxycarboxylic acids at a protoporphyrin IX cobalt(III) chloride modified glassy carbon electrode, J. Electroanal. Chem., 2005, $581,104-110$.

29 A.G.S. Prado, H.T. Barcelos, A.O. Moura, A.R. Nunes and E.S. Gil, Dichlorophenoxyacetic acid anchored on silica-gel modified carbon paste for the determination of pesticide 2,4-D, Int. J. Electrochem. Sci., 2012, 7, 8929-8939.

30 N. Maleki, A. Safavi and H.R. Shahbaazi, Electrochemical determination of 2,4-D at a mercury electrode, Anal. Chim. Acta, 2005, 530,69-74. 